Theories \& Applications, the International Edition

Printed Version : (ISSN 2090-5262)

Online Version : (ISSN 2090-5270)

July 2014, Volume 4, No. 2 Pages (89-92)

\title{
The Effect of Sports Vision Training on Performance of Table Tennis Amateurs.
}

Wafaa Hassan

Faculty of physical education for girls, Helwan University, Egypt.

\begin{abstract}
Vision may be the most variable and selective of all the senses. Attempting to observe the fast movements that occur in sports places a great demand on human vision. There is evidence that vision plays an important role in the perceptual ability of an athlete, corresponding proportionately to his motor response. The aim of this study is to evaluate the effects of sports vision training on the sensory and cognitive abilities and motor performance of table tennis amateurs. Thirty healthy, female, university level tennis players with normal vision participated in the study and were randomly allocated into two groups: group I (experimental, $n=15$ ) and group II (control, $n=15$ ). The experimental group underwent twelve weeks of vision training, occurring two days a week for 40 minutes per session. The control group was not provided any vision training. At the end of eight weeks, statistical analysis indicated significant improvement in the experimental group for all measured visual variables: reaction time, hand-eye coordination, visual acuity, and visual cognitive skills. In conclusion twelve weeks of visual calisthenics sessions resulted in improved reaction time, hand-eye coordination, visual acuity, and visual cognitive skills dynamics.
\end{abstract}

Keywords: Reaction Time, Eye Hand Coordination, visual cognitive skills.

\section{Introduction}

W hile physical sport is an ancient activity, vision is even older. The Egyptians had been taking part in sports for more than 2,000 years when the first ceremonial contests were held in Olympia in 776 BC. However, sports without vision is an unthinkable concept. Vision may be the most variable and selective of all the senses, and attempting to observe the fast movements that occur in sports places a great demand on the human body. There is evidence that vision plays an important role in the perceptual ability of an athlete, corresponding proportionately to motor response (Amr, 2005)

Sports action requires much more than the ability to see. The apparent paradox of having to see, yet perform competently without being able to see well, has brought about a division of emphasis in research into the role of vision in sporting action. Baseball, tennis, table tennis, badminton, ice hockey, and pelota are some of the ball games that provide rich examples of such action. Not surprisingly, sports experts refer to players having a "great eye," "superb vision," and "excellent peripheral vision." Such statements imply superior visual hardware and probably provided the impetus for sports vision research, which has a fairly lengthy history (Maman, et al, 2011).

Sports coaches, performers, and scientists are constantly on the lookout for new ways to enhance sports performance and gain competitive advantage. One of the latest techniques offered is visual training: a series of repetitive eye exercises prescribed by sports optometrists claiming to improve basic visual functions and, consequently, sports performance (Quevedo, et al, 1999).

Table tennis is a fast-moving sport, and it is very difficult for the average person to manage accurate umpiring, especially in basic skills, which usually take less than a second to complete. Success in table tennis depends on proper use of the player's basic skills, which include sending and receiving, different strokes, the need to see well, whether passing or receiving, and the ability to use the eye and its movement in the appropriate direction and speed to determine the path needed to achieve the movement objective. It is very important for the student to be aware of their movements and self-realization movements carried out by teammates. Visual perception and vision are importants element which affecting the progress and prosperity level of performance skills of the student. And falls visual sensation under the kinds of sensations required by sense organs distributed on the surface of the body or close to it, and plays a big role in human life, which lead the eye the role of the future of the sense of visual and availability of receiving and processing stimuli sensory (optical) of the objects or subjects of Foreign Affairs. And plays an important role visual sensation and a major role in various types of motor activity, which cooperates with all other types of sensations in awareness and understanding of the nature of motor performance, and matching conditions and the conditions of motor activity.

It is established that highly skilled players have better visual abilities than non-athletes (Christenson \& Winkelstein, 1988). The consensus is that expert and novice athletes are 
not differentiated solely by variation in basic visual skills, though several recent studies show that visual training can improve sports performance (Abernethy 1987; Starkes and Deakin 1984; Kluka et al, 1996).

According to Tate, although these studies highlight the potential of perceptual training programs, various shortcomings in the literature prevent a clear evaluation of their usefulness (Tate, et al, 2008). Most researchers have failed to use placebo or control groups in contrast to the training group. The observed improvement in performance may, therefore, be due to conformation bias or increased familiarity with the test environment rather than any meaningful training effect (Christina, et al, 1990). Additionally, researchers have neglected to use suitable transfer tests to examine whether training facilitated performance in a real world context (Farrow, et al, 1998).

Our body will only respond to what it can see. Despite this fact, little attention has been paid to vision. For decades, players have been told to "watch the ball" or "keep your eye on the ball." These phrases seem to be a maxim that should solve this problem when playing tennis. Remember, it is not hard to know what to do but how to do what you know! Not watching the ball is typically due to "visual wandering" and a lack of visual discipline or training. Running, acceleration, eye movement, and the speed of the ball are the visual spoilers.

Therefore, the aim of this study is to evaluate the effects of sports vision training on the sensory and cognitive abilities and motor performance of table tennis amateurs

\section{Material and Methods}

\section{Experimental approach}

Two groups (control and experimental) performed a pre- and post-training intervention designed to evaluate visual perceptual skills that were subdivided into seven categories: visual discrimination (VD), visual figure ground (VFG), visual closure (VC), visual sequential memory (VSM), visual form constancy (VFC), visual spatial relationships
(VSR), and visual-motor integration (VMI). Sports vision skills were also evaluated and were subdivided into visual reaction time (RT), hand-eye coordination (HEC), peripheral vision (PV), and depth perception (DP). These were measured during various table tennis maneuvers including topspin serve (TS), backspin serve (BS), forehand push (FP), and backhand push (BP). The experimental group completed a visual training program twice a week for twelve weeks, totaling 24 training sessions, in order to evaluate whether this training modality would have a positive, negative, or no effect on visual perceptual skills tests and sports vision skills in table tennis. Validity and reliability were assessed using a coefficient of variation on pretest measures. A good level of validity and reliability was observed.

\section{$\underline{\text { Participants }}$}

Thirty healthy, female, university level tennis players with normal vision participated in the study and were randomly allocated into two groups: group I (experimental, $n=15$ ) and group II (control, $\mathrm{n}=15$ ). Subjects were required to read and complete a health questionnaire and informed consent document. There was no history of coronary heart disease, diabetes, or recent surgery in any study participant.

\section{$\underline{\text { Training Protocol }}$}

The first step in improving an athlete's visual skills is to ensure that their eyesight is good. Sight refers to how well you can read the eye chart. Our twelve week, in-season training program consisted of a set head positioning, peripheral vision, and hand-eye coordination exercises

\section{Statistical Analysis}

All statistical analyses were calculated by the SPSS statistical package. The results are reported as means and standard deviations (SD). Differences between two groups were reported as mean difference $\pm 95 \%$ confidence intervals (mean diff $\pm 95 \% \mathrm{CI}$ ). Student's t-test for independent samples was used to determine the differences in visual parameters between the two groups. The $\mathrm{P}<0.05$ was considered as statistically significant.

\section{Results}

\section{Table 1}

Age and Anthropometric Characteristics of the Groups (Mean \pm SD)

\begin{tabular}{|c|c|c|c|c|c|}
\hline Group & $\mathrm{N}$ & Age $[$ years $]$ & Weight $[\mathrm{kg}]$ & Height $[\mathrm{cm}]$ & $\mathrm{BMI}\left[\mathrm{kg} / \mathrm{m}^{2}\right]$ \\
\hline Experimental & 15 & $18.73 \pm 0.7$ & $\mathbf{5 8 . 6} \pm 6.2$ & $161.9 \pm 4.5$ & $23.5 \pm 1.8$ \\
\hline Control & 15 & $18.53 \pm 0.5$ & $60.6 \pm 6.8$ & $163.6 \pm 3.3$ & $23.3 \pm 2.1$ \\
\hline
\end{tabular}

Table 1 shows Age and anthropometric characteristics of the subjects. There were no significant differences observed in the age and anthropometric characteristics for the subjects in the two different groups. 
Table 2

Mean \pm SD for sports vision variables and table tennis skills among the control and experimental groups

\begin{tabular}{|c|c|c|c|c|c|c|c|}
\hline \multirow[b]{2}{*}{ Variables } & \multicolumn{3}{|c|}{ Control } & \multicolumn{3}{|c|}{ Experimental } & \multirow[b]{2}{*}{ T sign } \\
\hline & Pre & Post & $\begin{array}{c}\text { Change } \\
(\%)\end{array}$ & Pre & Post & $\begin{array}{c}\text { Change } \\
(\%)\end{array}$ & \\
\hline \multicolumn{8}{|c|}{ Visual perceptual skills } \\
\hline VD & $11.4 \pm 2.4$ & $13.3 \pm 1.8$ & 16.95 & $10.5 \pm 4.01$ & $15.8 \pm 1.7$ & 50.96 & Sign \\
\hline VFG & $13.5 \pm 1.8$ & $14.2 \pm 1.4$ & 4.928 & $13.6 \pm 2.4$ & $15.3 \pm 0.7$ & 12.25 & Sign \\
\hline VC & $7.4 \pm 1.9$ & $8.2 \pm 1.0$ & 9.83 & $7.6 \pm 1.8$ & $8.5 \pm 1.2$ & 12.27 & Not Sign \\
\hline VSM & $3.9 \pm 1.4$ & $6.0 \pm 1.7$ & 55.19 & $4.6 \pm 2.9$ & $6.9 \pm 1.3$ & 50.71 & Sign \\
\hline VFC & $7.2 \pm 0.91$ & $9.7 \pm 1.1$ & 34.25 & $7.1 \pm 1.5$ & $10.2 \pm 1.4$ & 42.99 & Not Sign \\
\hline VSR & $20.6 \pm 5.4$ & $23.3 \pm 4.3$ & 13.26 & $19.9 \pm 5.3$ & $28.5 \pm 2.8$ & 42.80 & Sign \\
\hline VMI & $25.0 \pm 5.9$ & $26.9 \pm 4.9$ & 7.73 & $23.7 \pm 5.7$ & $31.4 \pm 1.4$ & 32.30 & Sign \\
\hline \multicolumn{8}{|c|}{ Sports vision skills } \\
\hline RT & $\mathbf{0 . 5 1} \pm \mathbf{0 . 0 3}$ & $0.46 \pm 0.09$ & 10.12 & $0.54 \pm 0.0 .9$ & $0.41 \pm 0.05$ & 23.47 & Sign \\
\hline HEC & $8.5 \pm 1.5$ & $10.7 \pm 1.3$ & 24.99 & $9.2 \pm 2.5$ & $14.9 \pm 2.1$ & 61.58 & Sign \\
\hline PV & $5.1 \pm 1.3$ & $6.5 \pm 0.9$ & 25.96 & $5.09 \pm 1.6$ & $8.0 \pm 1.4$ & 57.91 & Sign \\
\hline DP & $2.7 \pm 0.8$ & $4.5 \pm 0.8$ & 65.86 & $2.9 \pm 1.4$ & $6.0 \pm 1.1$ & 109.3 & Sign \\
\hline \multicolumn{8}{|c|}{ Basic table tennis skills } \\
\hline TS & $2.3 \pm 0.8$ & $3.9 \pm 0.6$ & 73.56 & $2.1 \pm 1.1$ & $4.5 \pm 0.5$ & 112.5 & Sign \\
\hline BS & $2.0 \pm 0.9$ & $3.5 \pm 0.5$ & 73.3 & $2.4 \pm 1.1$ & $3.9 \pm 0.6$ & 63.87 & Sign \\
\hline FP & $2.7 \pm 1.4$ & $4.5 \pm 0.9$ & 67.51 & $2.7 \pm 1.0$ & $5.7 \pm 1.3$ & 115.0 & Sign \\
\hline $\mathbf{B P}$ & $2.4 \pm 1.0$ & $4.2 \pm 0.8$ & 75.0 & $2.4 \pm 1.2$ & $5.4 \pm 1.3$ & 125.0 & Sign \\
\hline
\end{tabular}

Table 2 shows significant differences were seen between the post-tests of the experimental and control groups for all variables except $\mathrm{VC}$ and $\mathrm{VFC}(\mathrm{p} \leq 0.05)$.

\section{Discussion}

The primary findings from this study were the significant increases in all vision variables which proves the efficacy of visual training. The importance of vision in a sport is demonstrated in this study. Vision is the embodiment of a activity physical monopolizes $80 \%$ of the information provided by our five senses. The contribution of vision to sports is in the management of space (obstacles, color, brightness, etc.), anticipation, and monitoring of actions such as reaction speed and coordination of other athletes.

It was confirmed by Rateb that in order for a player to master a particular skill, he needs to perform this skill dozens of times (Rateb, 1995). In doing so, he strengthens and supports the neural pathways that control the muscles responsible for the performance of the skill. One example is that of a gymnast who uses his mental skills in an orderly fashion, leading to the active involvement of his muscles in order to perform the desired skill

We attribute the differences in the experimental group to the impact of the proposed training program. These exercises served to maintain the stability of the head, develop optical precision, improve distance vision, and improve visual perception. They directly impacted visual development as well as improved optical cognitive skills, which increased performance skill level of the students.
We believe that these exercises may introduce a visual thrill factor or excitement that causes students to accept it in a more positive manner.

In this regard, Seiller noted that some of the visual skills have a direct positive impact on the level of performance, while Variyadaan noted that athletes' visual skills were distinct from non-athletes (Seiller, 2004).

According to (Mohamed, 2004) vision has an important role in skill performance, especially beatings, rejection, and transmission, narrated that way can sport learn his whereabouts for the discount and determine the type of movements that can perform and understand mathematical through this sense the movements of rival, and thus can take the appropriate position, either offensive or defensive.

The results of the present study showed statistically significant improvement in the variables for two groups.

Amr (2005) demonstrated that visual training is important for athletes and non-athletes alike. Visual training must be exercised by everyone without exception in order to overcome the stress optic, which negatively affects visual function over time.

Williams confirmed this when he demonstrated the importance of vision as it plays a significant role in the process of motor learning (Williams et al., 2005). Sight's 
mechanism of action starts at the retina, the site on which the image forms. The retina then sends the image to a specialized agency of optical nerve cells optical in the back of the cerebral cortex, where interpretation of the information is formed. Any defect in the interdependence of body systems that lead to actions which bind the people have been speaking the wrong signals in the device, it must receive the information correctly to interpret correctly.

Good hand-eye coordination increases the player's ability to perform complex movements, respond effectively to external stimuli, and create fluid movements. With regard to table tennis, hand-eye coordination helps the player with proper positioning of the racquet, as well as control of arm velocity and direction of hit (Rodrigues et al., 2002).

The lack of difference between cognitive variables (VC and VFC) means that the ability to accurately define the forms and symbols despite the different sizes to move between the points specified sequence of sound and high speed, however, that there are many variables that may represent the difficulty of the student, which may affect the performance, namely, that it should be ready to face the ball from any angle or direction, the different path of the ball and speed, and angle of flight and gravity are all influential factors and distracting.

In this regard, Seiller found that the capacity for visual training can improve, which in turn is reflected at the level of performance skills (Seiller, 2004).

The results of this study are supported by the work of Maman, who indicated positive effects on the performance of table tennis after a specific visual training program (Maman, et al, 2011).

\section{Practical Applications}

Athletes and coaches are in continuous search of newer and better techniques to enhance performance. Vision plays a special role in athletic ability and can therefore function as a platform for this search. The results of the present study indicate that a visual skill training program improves the basic visual and cognitive skills, as well as the performance level in table tennis. Visual training is an adequate strategy for the organization of learning and training processes, having highly positive effects on sport of table tennis.

References

1. Abernethy B. Selective attention in fast ball sports: II. Expert-novice differences. Austral J Sci Med Sport, 1987;19: 7-16.

2. Amr H. A specific Visual Skills Training Programme Improves Fencing Performance Level, Visual Variables and Statics Balance,10th Annual Congress of the European College of Sport Since, Belgrade,316,2005.
3. Barry S. Positive Effects of a Visual Skills Development Program, Optometry\& Vision Science, 2004;79(5):279-280.

4. Christenson GN, Winkelstein, AM. Visual skills of athletes versus non-athletes: development of a sports vision testing battery. J Am Optometric Assoc., 1988; 59(9): 666-675.

5. Christina RW, Baressi JV, Shaffner P. The development of response selection accuracy in football linebackers using video training. Int $J$ Sports Sci., 1990; 20: 471-485.

6. Farrow D, Chivers $P$, Hardingham $C$, Sasche $S$. The effects of video based perceptual training on tennis return of serve. Int J Sports Psychol., 1998; 29: 231-242.

7. Kluka DA, Love PL, Kuhlman J, Hammach G, Wesson M. The effects of visual skills training program on selected collegiate volleyball athletes. Int J Sports Vision., 1996; 3:(1): 23-34.

8. Maman P, Sandeep K, Jaspal S. Role of Sports Vision And Eye Hand Coordination Training in Performance of Table Tennis Players, Brazilian Journal of Biomotricity, 2011; 5(2): 106-116

9. Osama R. Sport Psychology (concepts applications) - first edition , home of the Arab Thought.(in Arabic),11,1995.

10. Quevedo L, Solé J, Palmi J, Planas A, Saona C. Experimental study of visual training effects in shooting initiation. Clinical and Experimental Optometry, 1999; 82, 23-28.

11. Rodrigues ST, Vickers JN, Williams AM. Head, eye and arm coordination in table tennis. Journal of Sports Science, 2002; 20: 187-200.

12. Starkes JL, Deakin J. Perception in Sport: A cognitive approach to skilled performance. In Cognitive Sport Psychology. Lansing, NY: Sport Science Associate. 115-128.1984.

13. Tate B, Paul M, Sandhu JS. The Impact of Visual Skills Training Program on Batting Performance in Cricketers, Serbian Journal of Sports Sciences, 2008; 2(1): 17-23

14. Williams AM, Davids K, Williams JG. Visual Perception and Action in Sport, published in the Taylor \& Francis e-Library, 41,2005.

15. Zaki M. Vision visual skills of athletes (characteristics - factors - testing - training) in volleyball - Egypt's Library of the printing and publishing and distribution. (in Arabic ),12-33, 2004. 